\title{
Congenital hepatic fibrosis with an unusual pulmonary lesion
}

\author{
ROGER WILliAMS, PETER J. SCHEUER, AND BRIAN E. HEARD \\ From the Departments of Medicine and Pathology, Royal Free Hospital, London, \\ and the Department of Pathology, Postgraduate Medical School, London
}

SYNOPSIS The necropsy findings in a 5-year-old girl with congenital hepatic fibrosis are described. She had been followed since the age of 18 months and finally developed hepatocellular failure. Extensive haemorrhagic necrosis was found at necropsy and was probably related to the terminal illness. Other unusual findings were areas of typical post-necrotic cirrhosis and marked centrilobular and diffuse emphysema of the lungs. It is suggested that the latter was also congenital in origin.

A distinct form of hepatic fibrosis often occurring together with congenital cystic disease of the kidneys was first described by MacMahon in 1929. Although this had been thought to be a variant of congenital cystic liver it differs from the latter condition in several aspects. Large cysts are absent and the characteristic histological picture is of broad bands of mature fibrous tissue with relatively normal architecture in between. Kerr, Harrison, Sherlock, and Walker (1961) suggested the term 'congenital hepatic fibrosis' and stressed the frequent occurrence of portal hypertension, which is rare in simple cystic liver. The recognition of this condition is important, for liver cell function is usually well preserved and consequently these patients are good candidates for shunt operations.

Few cases have been studied both during life and at necropsy, and the purpose of this paper is to describe the findings in a 5-year-old child who was followed since the age of 18 months. She was of interest not only on account of certain hepatic changes found at necropsy but also because of the presence of an unusual pulmonary lesion possibly of congenital origin.

\section{CASE HISTORY}

The early history of this child has already been described in detail (case 1, Kerr et al., 1961). To summarize, she was the product of a normal pregnancy and delivery and had apparently developed normally until the age of 16 months. At that time abdominal distention was noted, and subsequent investigations in hospital revealed gross hepato-splenomegaly with normal liver function tests apart from a raised serum alkaline phosphatase level Received for publication 20 September 1963.
(64 King-Armstrong units). Other findings were a leucocytosis of 19,000 per c.mm. and a raised erythrocyte sedimentation rate of $35 \mathrm{~mm}$. in one hour. A chest radiograph showed an unusual appearance of fine miliary mottling throughout both lung fields. After an exploratory laparotomy during which a liver biopsy was taken she was discharged to be followed as an outpatient. Subsequent progress was disappointing, with a lag in growth and development. In 1959 the findings on investigation were essentially the same, with a rise of serum alkaline phosphatase level of $54 \mathrm{~K}$.-A. units and normal serum bilirubin level and flocculation tests. The electrophoretic pattern of the serum proteins, however, showed an increase in gamma globulin to $5 \cdot 1 \mathrm{~g}$. per 100 $\mathrm{ml}$. with a definite decrease in serum albumin $(2 \cdot 4 \mathrm{~g}$. per $100 \mathrm{ml}$.). Bromsulphthalein excretion was also impaired with $15 \%$ retention at 30 minutes. A diagnosis of congenital hepatic fibrosis was made, largely on the basis of the histological appearances in the previous operative liver biopsy, together with the relatively normal liver function tests. The changes in the chest radiograph, which were unaltered, were attributed to pulmonary microlithiasis. Both parents were examined at this time and had chest radiographs but no abnormalities were found.

In 1960 her condition began to deteriorate and in June she was admitted to hospital because of general malaise and fever of $102^{\circ} \mathrm{F}$. No cause for the pyrexia was found and the temperature settled spontaneously. A striking clinical sign at this time was severe dyspnoea, with respiratory rates varying between 30 and 40 per minute. She was also noted to be cyanosed. Examination of the chest, however, showed only a few scattered rales at the bases and sputum examination was repeatedly negative. She was readmitted for a similar episode in November, marked dyspnoea again being a puzzling feature. The white cell count was 23,800 per c.mm. with $78 \%$ polymorphs. A week after being discharged home she 
developed oedema of the ankles and was admitted to hospital semi-comatose with jaundice and hepatic foetor. Investigations showed a haemoglobin of $67 \%$ and white cell count of 38,000 per c.mm. ( $88 \%$ polymorphs). The serum bilirubin level was now raised (total $7 \cdot 1 \mathrm{mg}$., conjugated $6.1 \mathrm{mg}$. per $100 \mathrm{ml}$.) and a serum protein estimation showed $2.7 \mathrm{~g}$. albumin and $1.4 \mathrm{~g}$. globulin per $100 \mathrm{ml}$.

Despite treatment with Neomycin and intravenous dextrose her condition deteriorated and she died 24 hours later. At no time was there any definite evidence of haemorrhage from oesophageal varices.

\section{NECROPSY FINDINGS}

The body was generally wasted, with marked sacral oedema and abdominal distension. There were small pleural and pericardial effusions and approximately 1 litre of clear yellow fluid was present in the peritoneal cavity. Lymph nodes in the thoracic, cervical, and abdominal groups were slightly enlarged.

The upper air passages were congested and contained mucopus. The lungs were bulky and indurated, weighing $270 \mathrm{~g}$. (right) and $225 \mathrm{~g}$. (left). A recent infarct was seen on the surface of the left lower lobe. Sectioning of the right lung revealed diffuse emphysema and fine fibrosis. The left lung was examined after pressure-fixation with formalin and the changes are described in detail below. The heart appeared normal apart from dilatation of the ventricles.

No renal lesions were seen either macroscopically or on subsequent histological examination.

PATHOLOGY OF THE LIVER AND GASTROINTESTINAL TRACT The gall bladder and extrahepatic bile ducts appeared normal and were not dilated. The spleen (124 g.) was enlarged and soft. Culture of a splenic swab was negative but post-mortem blood culture yielded coliform organisms. The pancreas appeared normal. Varices were seen at the lower end of the oesophagus. No rupture was demonstrated and there was no blood in the stomach. The duodenum appeared normal. The jejunum was distended and purple in colour. Numerous small ulcers were seen in the distended ileum, the lumen of which contained blood clot and blood-stained mucus. The colon contained a little tarry material. Fresh thrombus occluded the portal, splenic, and superior mesenteric veins and extended for a few centimetres into the intrahepatic branches of the portal vein.

The liver weighed $625 \mathrm{~g}$. (normal approximately $600 \mathrm{~g}$.) and was enlarged to $16 \times 10 \times 8 \mathrm{~cm}$. The capsule was thickened and the surface uneven and pale. The greater part of the organ was extremely hard, and showed on sectioning a fine reticular fibrosis which separated the parenchyma into을 irregular islands measuring from 0.1 to $0.3 \mathrm{~cm}$. Intrahepatic bile ducts were dilated to a diameter of $\stackrel{\bar{s}}{+}$ $0.6 \mathrm{~cm}$. and contained inspissated bile. There was no들 obstruction to the bile ducts at the hilum and no음 isolated cysts were seen. Histologically the appear- $\frac{\bar{D}}{\bar{D}}$ ances in most areas were those of congenital hepatic尺 fibrosis (Fig. 1). Septa of mature fibrous tissue were sharply demarcated from a slightly fatty parenchyma $\vec{\circ}$ the lobular structure of which was normal, with:liver cell plates one cell thick. The septa contained $\overrightarrow{\vec{\omega}}$ numerous well-formed bile ducts and were lightlys infiltrated with acute and chronic inflammatory? cells. Portal vein branches were inconspicuous in small portal areas but appeared normal in largerị tracts.

A few areas of haemorrhagic liver tissue were seen macroscopically, most of them near the hilum. These were softer in consistency than the rest of the organ. Histological examination of these areas showed haemorrhagic necrosis superimposed on the pattern of congenital fibrosis described above. The central ${ }_{-}^{-}$ parts of the lobules were most affected but in places whole lobules were destroyed. No evidence of re-. generation was seen in these areas. Many of the? portal vein branches contained recent thrombus.

Scattered throughout the finely fibrotic liver there were a few larger irregular scars measuring up to $1.0 \mathrm{~cm}$. across. Microscopically these were seen to be composed of poorly cellular fibrous tissue with $a \overrightarrow{\overrightarrow{0}}$ few islands of surviving parenchyma. Many of the $\frac{0}{3}$ latter had lost the normal lobular architecture and? were composed of plates several liver cells thick, ando thus had the appearance of typical regeneration nodules (Fig. 2). Connective tissue stains showed the presence in these larger fibrous scars of occluded $\frac{5}{3}$ veins in which thrombosis had presumably occurred in the past.

Sections of the liver biopsy taken three years before death showed changes of congenital hepatio음 fibrosis similar to those described above. Bile ducts $\frac{D}{2}$ however, were larger and more closely packedㅡㅡㄹ There was also more inflammatory cell infiltration $N$ and the junctions between parenchyma and septa were less well defined.

PATHOLOGY OF THE LUNG LESION The left lung was prepared for examination with the dissecting microso scope. Bronchi were sucked clear of mucus and ats cannula tied into the main bronchus. A pressure of 25 to $30 \mathrm{~cm}$. of $20 \%$ formalin was applied to the airways continuously for three days by means of art apparatus previously described (Heard, 1960). Slices? $0.8 \mathrm{~cm}$. thick were cut sagittally. Examination aftę barium sulphate impregnation showed two types of lesion of the air spaces. The first was a variety of 
FIG. 1. Typical appearances of congenital hepatic fibrosis. Broad bands of fibrous tissue separate and surround liver lobules (haematoxylin and eosin $\times 40$ ).

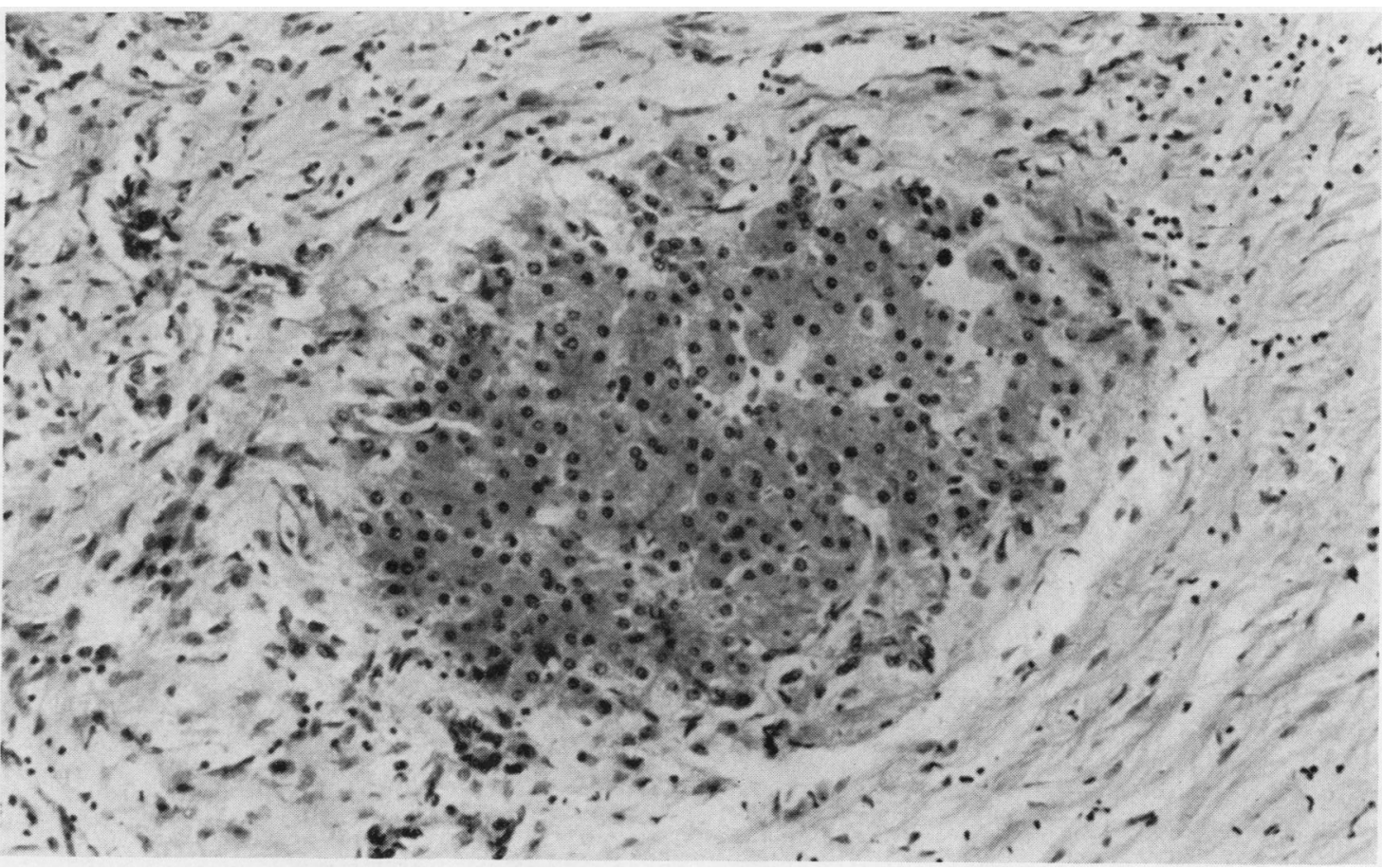

FIG. 2. Regeneration nodule seen in one of the larger irregular scars in the liver (haematoxylin and eosin $\times 160$ ). 


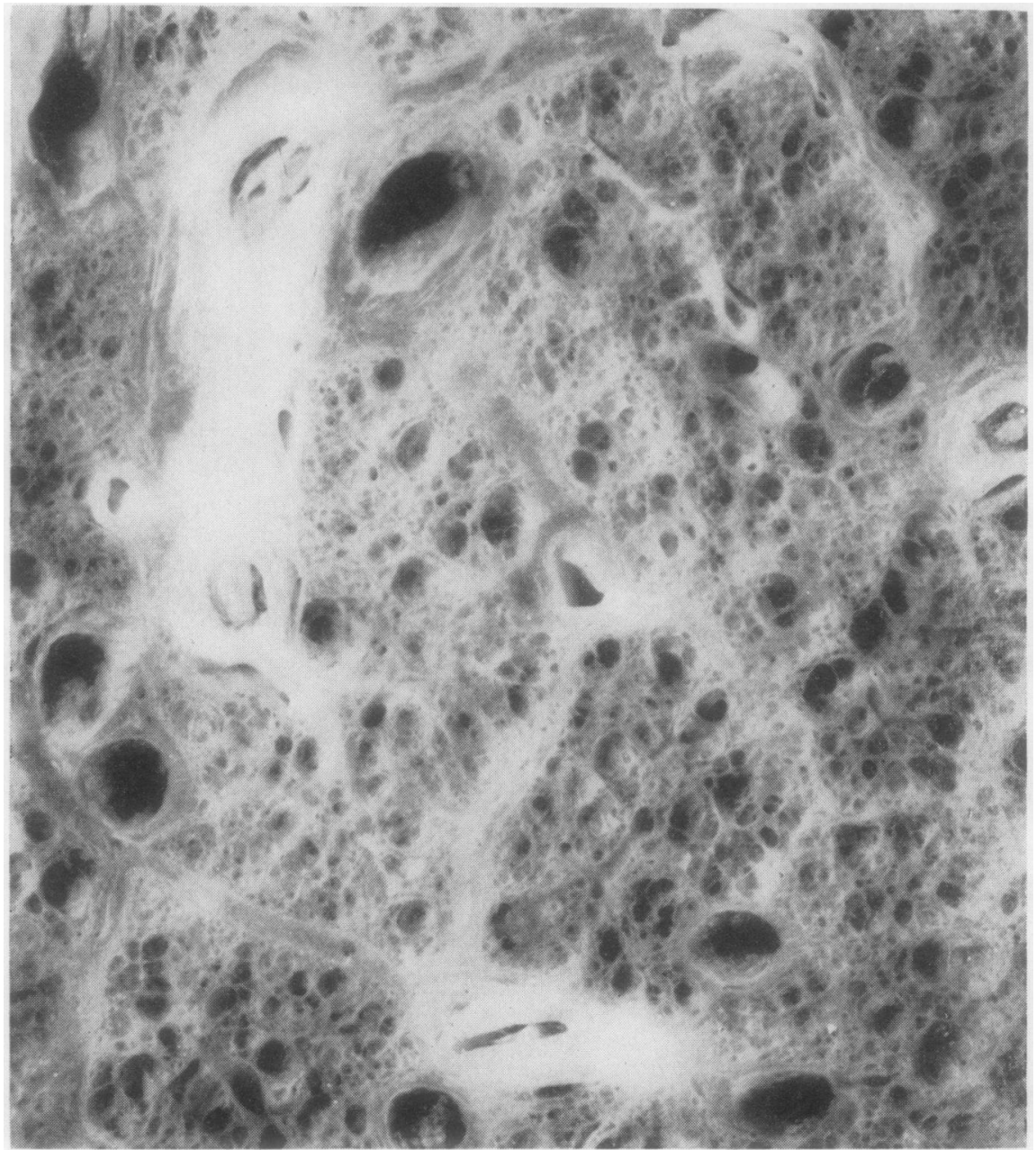

FIG. 3. Cut surface of left lower lobe of lung to show large numbers of dilated respiratory bronchioles in all parts of the field. There is thickening of the septal, peribronchial and perivascular connective tissue and $\vec{V}$ several large pulmonary arteries (with white walls) contain organizing thrombi/emboli (pressure-fixation, barium sulphate, $\times 4 \cdot 8)$.

centrilobular emphysema consisting of dilatation of respiratory bronchioles (Fig. 3). These lay in an intermediate position in the secondary lobule and communicated freely with normal looking terminal bronchioles nearer the centre of the lobules and a small number of remaining alveoli peripherally (Fig. 4). The dilated bronchioles were up to $0.5 \mathrm{~mm}$. or sometimes $1 \mathrm{~mm}$. across, and an cxceptional space measured $3 \mathrm{~mm}$. The walls of some air spaces were thicker than others, suggesting perhaps an origin from earlier orders of respiratory bronchioles. Occasionally it was suspected that terminal bronchioles were cystic, but this could not be proved, since alveoli could have been lost during dilatation. Where the lobules met septa and pleura, there was often an increase in thickness of alveolar walls. Sometimes no alveoli remained beyond the dilatations.
The second type of lesion seen with the dissecting microscope was diffuse emphysema, or panacinas emphysema. This was identified as thinning or loss of air space walls in all parts of the lobules (Fig. 5) They were often reduced to very thin membranes of to strands by the apparent atrophy of respiratoræ tissue, and the pulmonary arteries became more prominent than usual. Pulmonary capillaries weres probably reduced because the walls were much pale than usual. It was noticed that diffuse emphysemep was present alongside centrilobular emphysema, as is often the case in adults' lungs.

The dilatation of air spaces was not due to pressure, for control material from a girl of $6 \frac{1}{2}$ years fixed in the same way, showed smaller airways respiratory bronchioles measuring $\mathbf{0 . 2} \mathrm{mm}$. acros and alveoli $0 \cdot 1 \mathrm{~mm}$. (Heard, 1959).

Histologically only a little additional information 


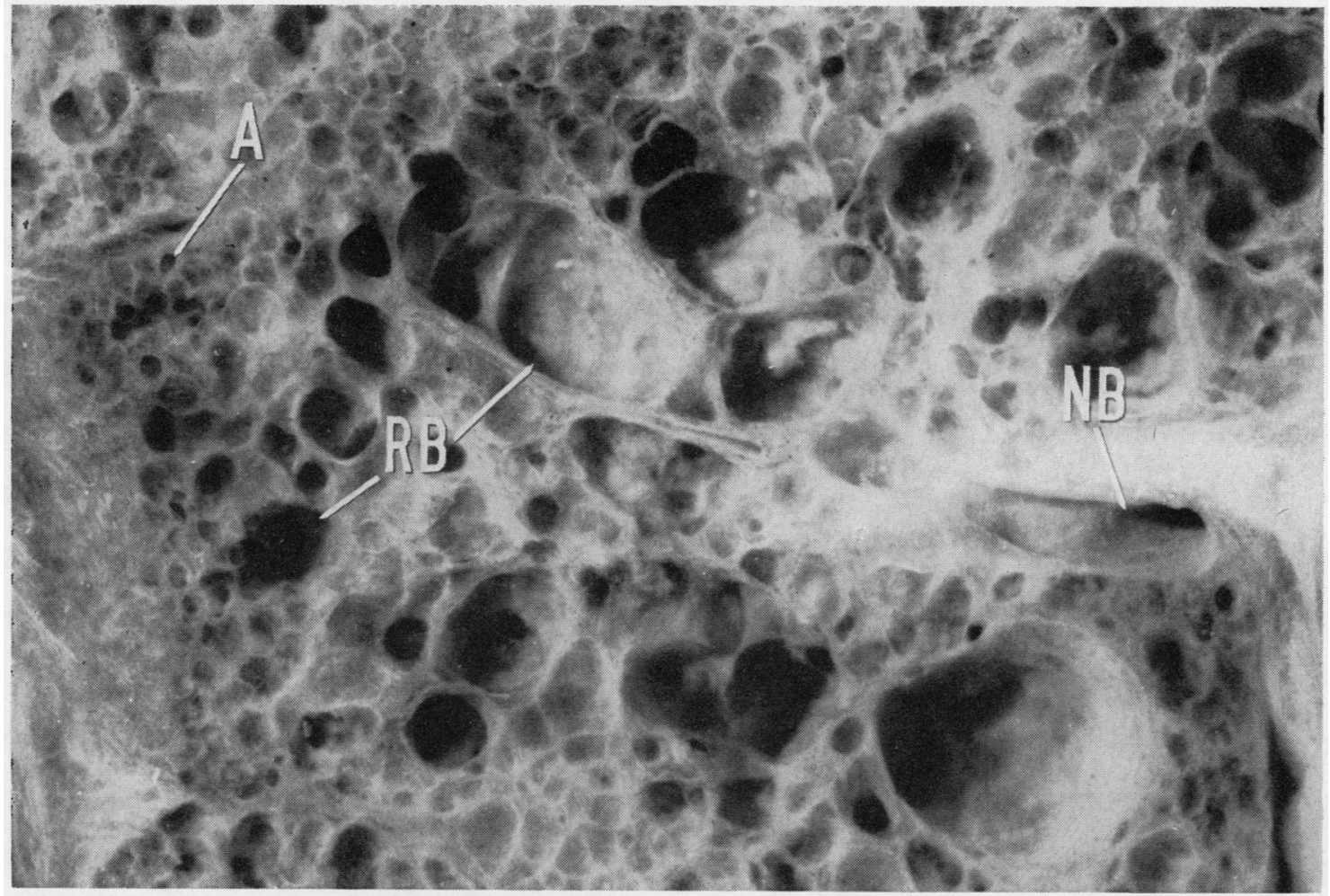

FIG. 4. Cut surface of left lung to show centrilobular emphysema. A non-respiratory bronchiole (NB) leads to the centre of the lobule and divides into a number of dilated respiratory bronchioles $(R B)$. There are some intact alveoli $(A)$ out near the edge of the lobule (pressure-fixation, barium sulphate, $\times 17 \cdot 6$ ).

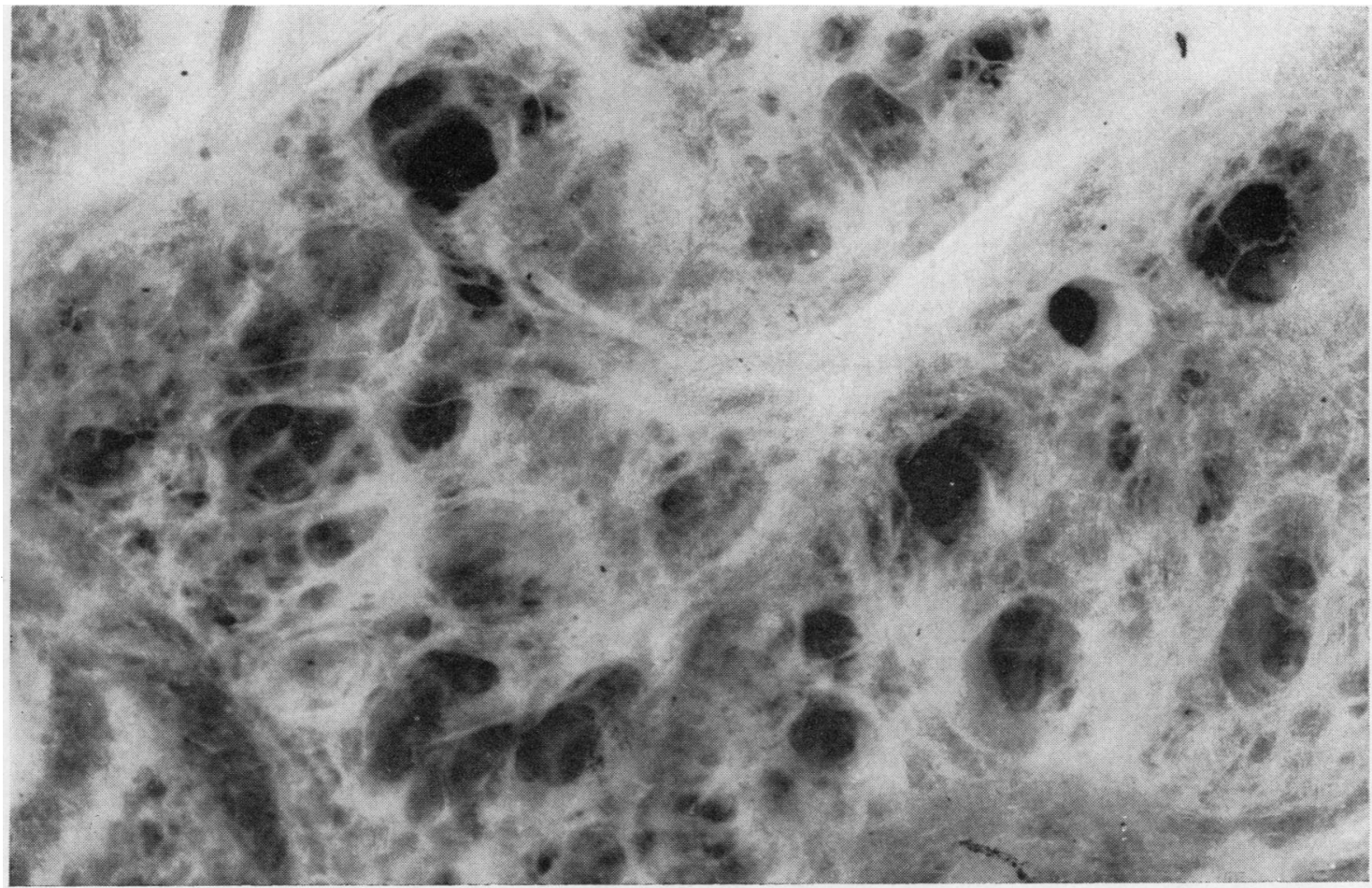

FIG. 5. Cut surface of left lung to show centrilobular and diffuse emphysema combined. Besides a number of dilated respiratory bronchioles there is a diffuse thinning of all air-space walls. Compare with Fig. 4 (pressure-fixation, barium sulphate, $\times 17 \cdot 6)$. 


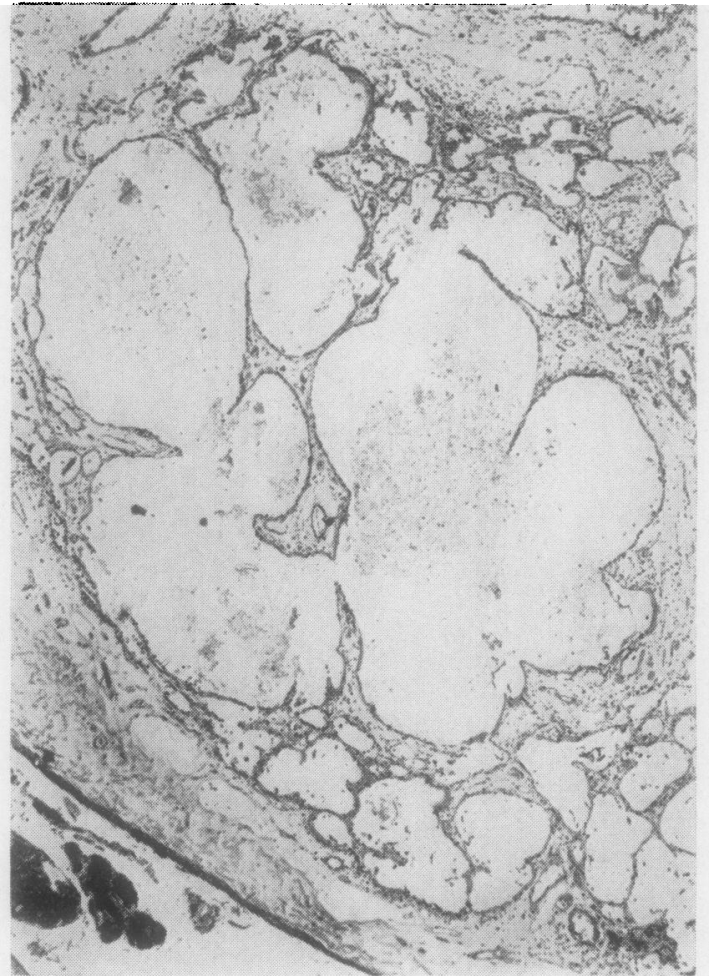

FIG. 6

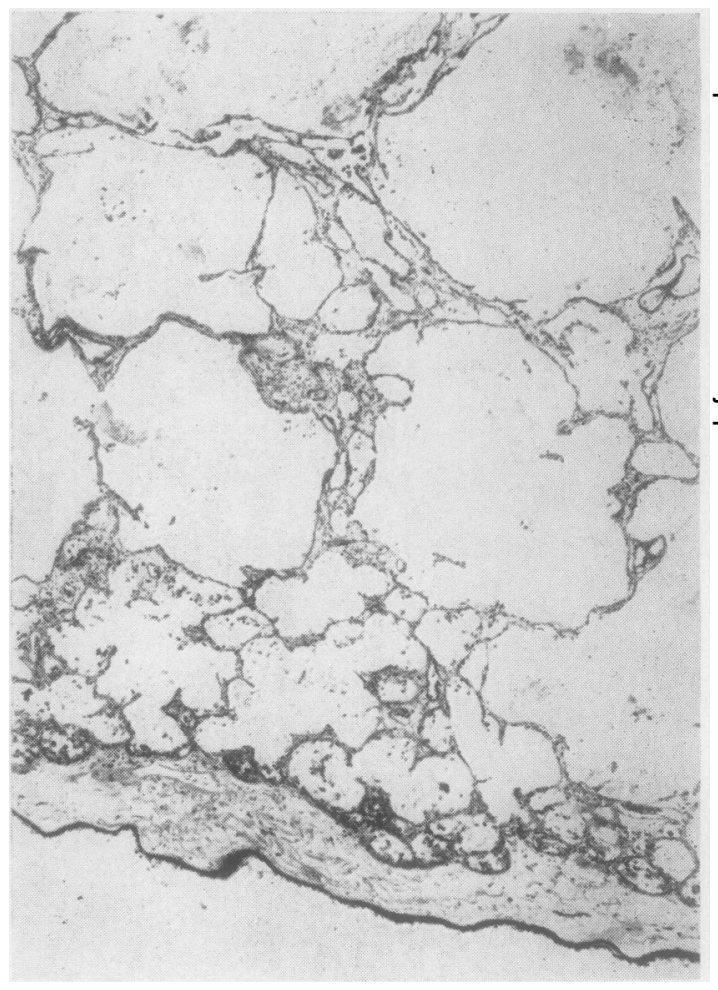

FIG. 7

FIG. 6. Centrilobular emphysema. A cluster of dilated respiratory bronchioles is surrounded by only a few alveoli. There is abundant connective tissue about (haematoxylin and eosin $\times 38$ ).

FIG. 7. Centrilobular emphysema. A lobule just beneath the pleura with intact alveoli peripherally but very few alveoli around the dilated respiratory bronchioles. Note the broad band of loose connective tissue just beneath the pleura (haematoxylin and eosin $\times 38$ ).

was obtained. Loose connective tissue was increased in amount in septa and in some adjacent alveolar and bronchiolar walls (Figs. 6,7); small vessels lay in this connective tissue and some lymphocytes and a few siderocytes were scattered here and there. In one area there was a small cluster of smooth muscle cells. Collagen fibres and reticulin fibres but no elastic fibres were present. Elastic fibres were scattered through the walls of the normal and dilated air spaces in roughly equal frequency to those in the control lung. Bronchi were normal in diameter and all the various elements of their walls, viz., epithelium, muscle, glands, and cartilage, were normal. A few large pulmonary arteries contained organizing emboli (Fig. 3).

\section{DISCUSSION}

Many of the findings in this case are in accord with previous descriptions of congenital hepatic fibrosis.
The clinical features of marked hepatomegaly together with portal hypertension, as evidenced by the presence of oesophageal varices, and relativelyo normal liver function tests apart from a raised serum? alkaline phosphatase level, should always suggesto the possibility of this disease (Kerr et al., 1961). The histological changes in the operative liver biopsyo and in the greater part of the liver at necropsy, as 0 well as the extreme hardness of the organ, were also N characteristic. Between the bands of fibrous tissue $\sigma$ the lobular architecture was normal. Other striking findings were the abundance of well-formed bile ducts in the fibrous bands and the paucity of smallo portal vein branches. These features have also been noted by other workers (Grumbach, Bourillon, andō Auvert, 1954; MacMahon, 1929; Parker, 1956). $\overrightarrow{\mathbb{\Phi}}$ Indeed, MacMahon described the condition as a命 congenital hyperplasia of the interlobular bile ducts. $\square$ Anomalies of the extrahepatic bile ducts were also present in several of the reported cases and it haso 
been suggested that their presence is more likely if the serum alkaline phosphatase is raised. In the present case, however, the extrahepatic biliary tree was entirely normal though the alkaline phosphatase level was considerably raised.

There were several unusual features. Parts of the liver showed haemorrhagic necrosis at necropsy. This was clearly of recent origin and probably corresponded in time to the terminal episode of hepatic failure. The occurrence of such necrosis could be due to a period of shock with lowered arterial pressure. The extensive portal venous thrombosis might also be secondary to a period of sluggish blood flow. Episodes of hepatic failure with histological evidence of necrosis may occur in cirrhosis following oesophageal haemorrhage. In congenital hepatic fibrosis liver failure has also been described following haemorrhage from varices, and in case 9 of the series of Kerr et al. (1961), a patient who had had several episodes of bleeding, there was slight centrilobular necrosis in the liver biopsy. In the present case, however, there was no definite evidence of preceding haemorrhage although the presence of varices was demonstrated both during life and at necropsy. Some melaena occurred after admission but was probably related to the ulceration found in the ileum at necropsy. Haas (1960) has described the case of a 2-year-old child with congenital hepatic fibrosis in whom gross ascites and oedema developed in association with signs of a bronchopneumonia. There was no preceding haemorrhage. The child died a week after presentation and the liver at necropsy was reported as showing destruction of the normal lobular pattern.

It is clear, however, that in our case episodes of necrosis had occurred before. The presence of local areas having the features of post-necrotic cirrhosis was of considerable interest and has not previously been recorded in congenital hepatic fibrosis. The lesion of post-necrotic cirrhosis does not necessarily imply a preceding viral hepatitis but simply indicates a particular and possibly recurring sequence of necrosis and regeneration. Popper, Rubin, Krus, and Schaffner (1960), for instance, have described the typical changes of this lesion in alcoholic patients with cirrhosis who, as a result of advances in medical treatment, had survived repeated episodes of liver failure. The cause of the previous necrosis in the present case is uncertain but it is of interest to note that more inflammatory cell infiltration was noted in the biopsy taken at $\mathbf{1 8}$ months than is usual in congenital fibrosis. Little is known, however, about the development of this condition. In most of the reported cases, as in this instance, hepatomegaly has been noted at an early age and the maturity of the fibrous tissue present would also be in keeping with a congenital defect. On the other hand, one of the children described by Kerr et al. (1961) had been previously examined at the age of $2 \frac{1}{2}$ years when hepatomegaly was not present.

The lung lesion in this case is also unexplained. At the Ciba Guest Symposium held in London in 1958 , emphysema was defined as a condition of the lung characterized by increase beyond the normal in the size of air spaces distal to the terminal bronchiole either from dilatation or from destruction of their walls. In the present case the changes are in that region and if we keep to the above definition they must be termed emphysema and not congenital cystic disease of the lung. Adult examples of centrilobular and diffuse (panacinar) emphysema as prepared by the present methods have been reported previously (Heard 1958, 1959, 1960). Emphysema of this type and severity, however, is very unusual in a child of this age in our experience. Possibly it also had a congenital basis. If the full complement of succeeding orders of respiratory bronchioles failed to develop, those bronchioles present may dilate with the growth of the child and enlargement of the thoracic cage. Such deformed air spaces would become infected easily and perhaps episodes of inflammation caused the superimposed diffuse emphysema in some of the lobules. During life, our patient had a persistent leucocytosis and was admitted on two occasions with an unexplained pyrexia. In retrospect, it seems likely that these episodes were due to pulmonary infections, although at no time were there any localizing features on examination and on chest radiographs. The sputum was invariably scanty and negative on culture. Another possible explanation for the fever is recurrent Gram-negative septicaemia. There are three other cases of congenital hepatic fibrosis in the literature with septicaemia (Campbell, Bick, Paulsen, Lober, Watson, and Varco, 1958; Kerr et al., 1961) and perhaps these children, like adults with cirrhosis, are unduly susceptible to such infection.

The unusual radiological appearances of the lungs during life with a diffuse miliary mottling are difficult to explain. These remained unchanged during the whole period of observation. They must have been produced by increased connective tissue in the lung and fewer air spaces.

We have been unable to find any previous account of similar pulmonary lesions, or of cystic lung, in reported cases of congenital hepatic fibrosis (Blakemore, 1947; Dustin, 1952; Grumbach et al., 1954; van der Schoot, 1955; Parker, 1956; Krainer, 1957; Campbell et al., 1958; Ivemark, Oldfelt, and Zetterström, 1959; Haas, 1960; Hickie and Garvan, 1962). The recognition of emphysema, however, at 
least of the mild grades, requires special fixation methods, and the investigation of similar cases along these lines may reveal further examples. Anomalies in other sites are common in congenital hepatic fibrosis. Congenital cystic disease of the kidneys and malformation of the bile ducts have been mentioned above. Others recorded are cystic pancreas, cerebral aneurysm, meningo-encephalocoele, cleft palate, atresia of the larynx, and dislocation of the toes. None of these was found in the present case and it is clear that the spectrum of associated abnormalities varies widely from case to case, and this must be taken into account in any consideration of the primary defect in this disease.

We should like to thank Professor Sheila Sherlock and Dr. I. G. Wickes for permission to report this patient. The photographs of the lung sections were taken by
Mr. W. Brackenbury of the Postgraduate Medical School, London.

\section{REFERENCES}

Blakemore, A. H. (1947). Surg. Gynec. Obstet., 84, 645. Campbell, G. S., Bick, H. D., Paulsen, E. P., Lober, P. H., Watson,
C. J., and Varco, R. L. (1958). New Engl. J. Med., 259, 904.

Dustin, P. (1952). Acta gastro-ent. belg., 15, 313.

Grumbach, R., Bourillon, J., and Auvert, J. P. (1954). Sem. Hop. 으 Paris, (Arch. Anat. path.), 30, A74.

Haas, L. (1960). Proc. rov. Soc. Med., 53, 327.

Heard, B. E. (1958). Thorax, 13, 136.

- (1959). Ibid., 14, 58.

- (1960). Amer. Rev. resp. Dis., 82, 792.

Hickie, J. B., and Garvan, J. M. (1962). Aust. Ann. Med., 11, 260. Ivemark, B. I., Oldfelt, V., and Zetterström, R. (1959). Acta paediat (Uppsala), 48, 1.

Kerr, D. N. S., Harrison, C. V., Sherlock, S. and Walker, R. M (1961). Quart. J. Med., 30, 91.

Krainer, L. (1957). Gastroenterology, 33, 265.

MacMahon, H. E. (1929). Amer. J. Path., 5, 499.

Parker, R. G. F. (1956). J. Path. Bact., 71, 359.

Popper, H., Rubin, E., Krus, S., and Schaffiner, F. (1960). Gastroenterology, 39, 669.

Schoot, J. B. van der (1955). Ned. T. Geneesk., 99, 2579. 